\title{
AVALIÇÃO DA DIMINUIÇÃO DO TEOR DE UMIDADE AO LONGO DA TELA DE UMA PENEIRA VIBRATÓRIA APLICADA A PROCESSO DE SEPARAÇÃO SÓLIDO- LÍQUIDO
}

\author{
T. S. A. SANTIAGO ${ }^{1}$, V. P. BARBOSA ${ }^{1}$, A. L. MENEZES ${ }^{1}$, R. GEDRAITE ${ }^{1}$ e C. H. \\ ATAÍDE ${ }^{1}$ \\ ${ }^{1}$ Universidade Federal de Uberlândia, Faculdade de Engenharia Química \\ E-mail para contato: rgedraite@ ufu.br
}

\begin{abstract}
RESUMO - Em processos de perfuração de poços de petróleo, a broca corta a rocha por onde passará o óleo contido no poço. Para realizar o transporte do sólido gerado pelo corte das rochas de volta à superfície, é utilizado fluído de perfuração, que posteriormente deve ser separado destes sólidos por uma unidade de controle de sólidos. O primeiro equipamento da linha de controle de sólidos durante a perfuração de um poço é a peneira vibratória. Neste trabalho foi abordado o processo de separação sólido-líquido utilizando o peneiramento vibratório, no qual foram realizados experimentos referentes ao deságue da suspensão alimentada ao longo da tela de separação. Foi empregado um simulante de fluido de perfuração tipicamente empregado em perfuração de poços de petróleo, composto por areia e água com espessante goma Xantana. Os resultados obtidos sugerem que o deságue é mais efetivo no trecho inicial da tela de separação que está mais próximo da calha de alimentação.
\end{abstract}

\section{INTRODUÇÃO}

Quando se é descoberto um novo poço de petróleo, dá-se início ao estudo da viabilidade econômica de exploração deste. Caso seja comprovada essa viabilidade, inicia-se o processo de perfuração do poço, onde uma broca perfura a rocha, abrindo o poço, por onde escoará o petróleo. O fluído de perfuração é utilizado neste processo, sendo injetado a partir da superfície pelo interior da coluna da perfuração e saindo pela ponta da broca. Seu retorno de volta à superfície ocorre através pelo espaço anular entre a coluna de perfuração e a parede do poço. Este fluído tem como finalidade estabilizar as paredes do poço, lubrificar a coluna, selar fissuras na parede do poço, arrefecer a broca e carrear até a superfície os sólidos provenientes da perfuração, entre muitas outras (ASME, 2005). A mistura contendo os sólidos provenientes da rocha e o fluído de perfuração deve ser separada, com a finalidade de recondicionar o fluído para o processo de perfuração e retirar o máximo possível o teor de umidade residual dos sólidos, sendo o tratamento do fluído de perfuração de suma importância do ponto de vista ambiental, econômico e operacional (Mattaet al., 2015).

Para o processo de separação da mistura sólido-líquido, é utilizada uma unidade de controle de sólidos, composta, frequentemente, de: peneira vibratória, bateria de hidrociclones e centrífugas decantadoras (Lobato et al., 2011), podendo haver variações com emprego de 
outros equipamentos nestas unidades de controle de sólidos. Vale destacar que, segundo Rajaet al.(2012), as peneiras vibratórias são os equipamentos mais comuns e utilizadosnos processos de separação sólido-líquido em processos de perfuração de poços de petróleo.

Devido à importância deste equipamento e complexidade em relação ao grande número de variáveis que ele apresenta, o efeito de algumas variáveis operacionais sobre o desempenho do peneiramento vibratório tem sido alvo de investigação de diversos autores (Guerreiro et al.2015).

Há diversos tipos de peneiras vibratórias, com diferentes movimentos de tela, utilizadas no processo de separação sólido-sólido e sólido-líquido. Em processos como o citado neste trabalho, o objetivo é a separação sólido-líquido.

Segundo Guerreiro et al. (2015), durante o processo separação ocorre a passagem de partículas menores do que a abertura da tela juntamente com o fluido presente. Por outro lado, as partículas maiores, retidas pela tela, serão separadas e encaminhadas para o processo posterior de secagem e, na sequencia, descarte junto ao meio ambiente.

Este trabalho focou na fase de secagem do material retido pela tela da peneiraao longo do processo de separação, sendo recolhidas amostras em diferentes pontos da tela para diferentes condições operacionais, com a finalidade de monitorar como ocorre o deságue da suspensão ao longo do comprimento da tela de separação da peneira vibratória.

\section{MATERIAIS E MÉTODOS} Figura 1.

A bancada experimental utilizada para a realização destes experimentos é mostrada na

Figura 1 - (1) Calha de alimentação (2) Peneira com tela de 175 mesh (3) Motovibradores (4) Inversor de frequência (5) Recipiente de coleta material retido (6) Tanque de material passante (7) Bomba de retorno do passante (8) Placa de aquisição de dados (9) PC (10) Bomba Recirculação/alimentação (11) tanque de alimentação (12) Medidor Coriolis

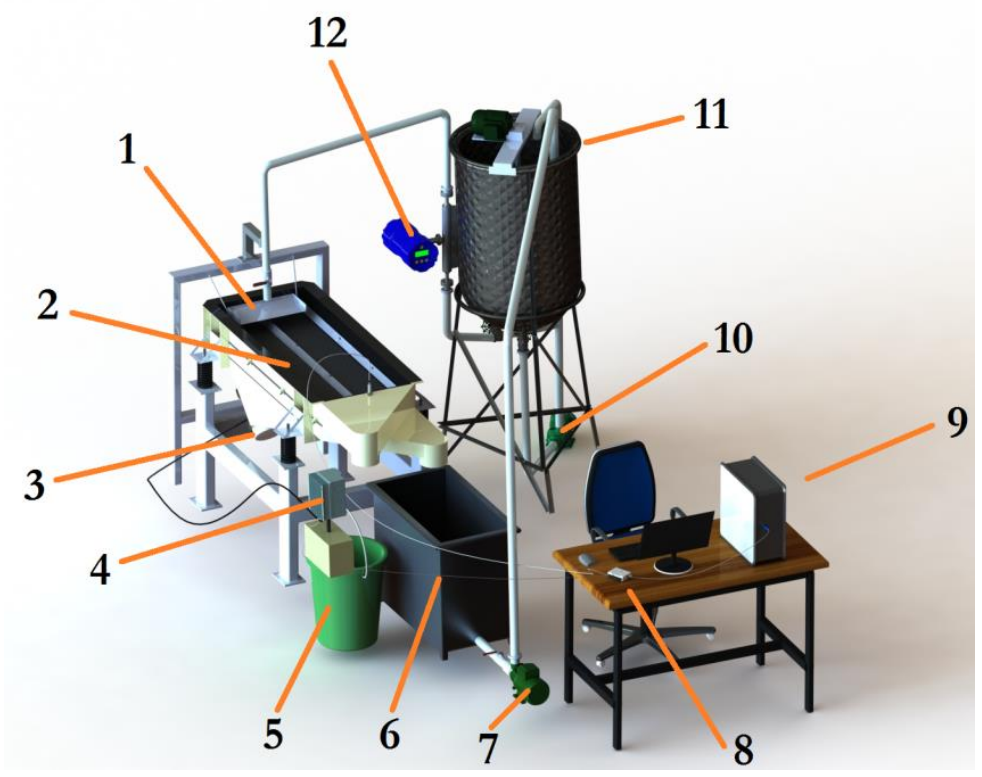


A peneira utilizada é produzida pela empresa Vibrokrafte possui dois motovibradores modelo VR4-07, responsáveis pelo movimento de vibração da tela de separação. Foi utilizada a tela de 175 mesh, com $95 \mu \mathrm{m}$ de abertura,fabricada pela empresa Tegape. A suspensãofoi armazenada no tanque de alimentação com capacidade para aproximadamente 500 litros, sendo alimentada na parte superior da peneira através de uma tubulação que a descarrega numa calha de alimentação.Sua vazão é controlada através de uma válvula manual e medida através de um medidor Coriolis, modeloTCM028K. Os sólidos úmidos retidos pela tela da peneira foram armazenados numrecipiente plástico posicionado na saída de material retido, enquanto o fluído que passa pela tela com os sólidos mais finos vão para o tanque de coleta de passante, por outra saída.

O sistema conta com duas bombas centrífugas para a movimentação do fluido, uma para retorno do material passantecontido no tanque de passante para o tanque de alimentação, e a outra no sistema de recirculação/alimentação da peneira. $O$ sistema de recirculação/alimentação da peneira conta com uma bifurcação na tubulação logo após o recalque da bomba, com uma válvula em cada uma das tubulações originadas a partir da bifurcação. Uma das válvulas regula a recirculação responsável por manter a suspensão homogenia no tanque, já a outra regula a vazão de alimentação.

A variável força-g da peneira, imposta pela ação dos motovibradores, é controlada por um sistema de controle proporcionalimplementado no software Labview ${ }^{\mathrm{TM}}$, que é processado por um PC presente na bancada ao lado, o sinal da força-g é obtido através de um acelerômetro modelo PCB 646B00e enviado ao PC. O sistema de controle atua na rotação dos motovibradores através de um inversor de frequência modelo WEG CFW700, variando assim a variável força-g. A comunicação entre o inversor de frequência, o PC e o acelerômetro é realizada por meio da placa de aquisição de dados da National Instruments USB 6008

Para a realização dos experimentos, foi preparada uma suspensão composta de 200 litros de água com 200 gramas de goma xantana com 24 quilos de areia padronizada, composta por 3 frações de massas iguais de areia com granulometria variando entre 0,15 e 1,2mm. A mistura final continha uma concentração volumétrica de sólidos de $5 \%$, sendo homogeneizada no interior do tanque de alimentação. $O$ teor de umidade, em base úmida, do sólido presente na corrente de alimentação era da ordem de $89,2 \%$.

Os experimentos foram feitosde acordo com as combinações de força-g e vazão de alimentação apresentados na Tabela 1 abaixo, para um planejamento $3^{\mathrm{k}}$ :

Os valores de força- $g$ estudados foram: 2,4 e 6 , relativos aos níveis $-1,0$ e +1 respectivamente. Já as vazões de alimentação foram: 10,18 e $26 \mathrm{~kg} / \mathrm{min}$, correspondentes aos níveis $-1,0 \mathrm{e}+1$, respectivamente. 
Tabela 1 - Planejamento $3^{\mathrm{k}}$ com as variáveis codificadas para os experimentos

\begin{tabular}{cc}
\hline Força-g & Vazão de alimentação \\
\hline-1 & -1 \\
-1 & 0 \\
-1 & +1 \\
0 & -1 \\
0 & 0 \\
0 & +1 \\
+1 & -1 \\
+1 & 0 \\
+1 & +1
\end{tabular}

Os pontos de coleta ao longo da tela de 1,1 metro de comprimento foram igualmente espaçados a partir da calha de alimentação, de acordo com o mostrado na Figura 2, sendo considerados 04 pontos de coleta:

Figura 2 - Pontos de coleta de material retido ao longo da tela

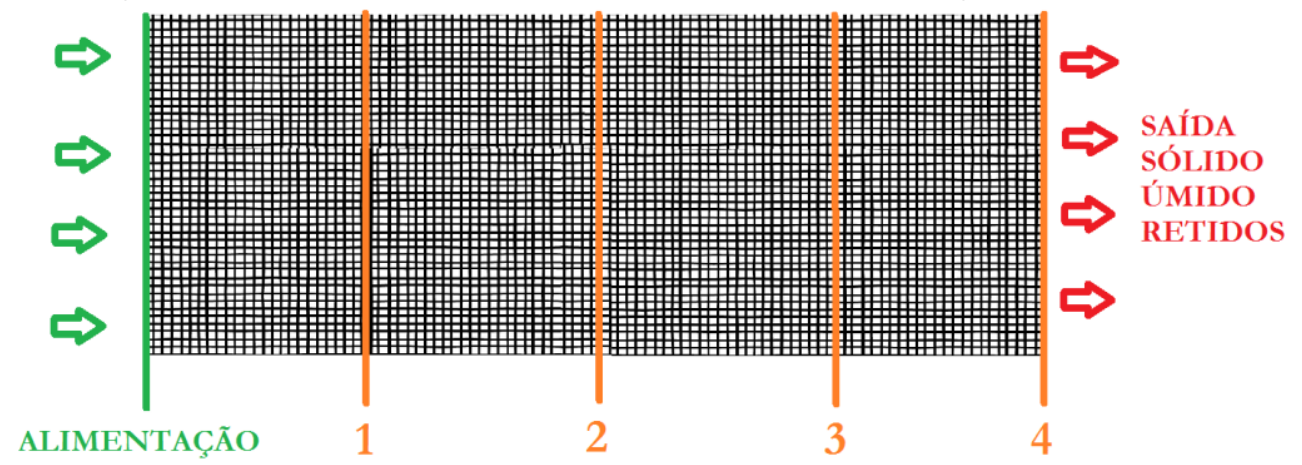

Foram coletadas 03 amostras para cada ponto da tela apresentado na Figura 2. Cada coleta teve duração de 1 minuto, seguida de mais 1 minuto de tempo de espera para se iniciar a nova coleta. As coletas eram iniciadas no ponto 4e eram realizadas em direção ao ponto 1 .

A Equação (1), utilizada para o cálculo de umidade residual dos sólidos retidos $(H$ ), foi calculada em base úmida, eleva em conta a massa do material úmido $\left(M_{H}\right)$ e $\operatorname{seco}\left(M_{S}\right)$ após 24 horas na estufa a $105^{\circ} \mathrm{C}$.

$$
H=\frac{M_{H}-M_{S}}{M_{H}}
$$




\section{RESULTADOS E DISCUSSÃO}

Os resultados obtidos com base nos experimentos realizados são mostrados na Figura 3, apresentada na sequencia.

Figura 3 - Resultados de umidade residual ao longo da tela
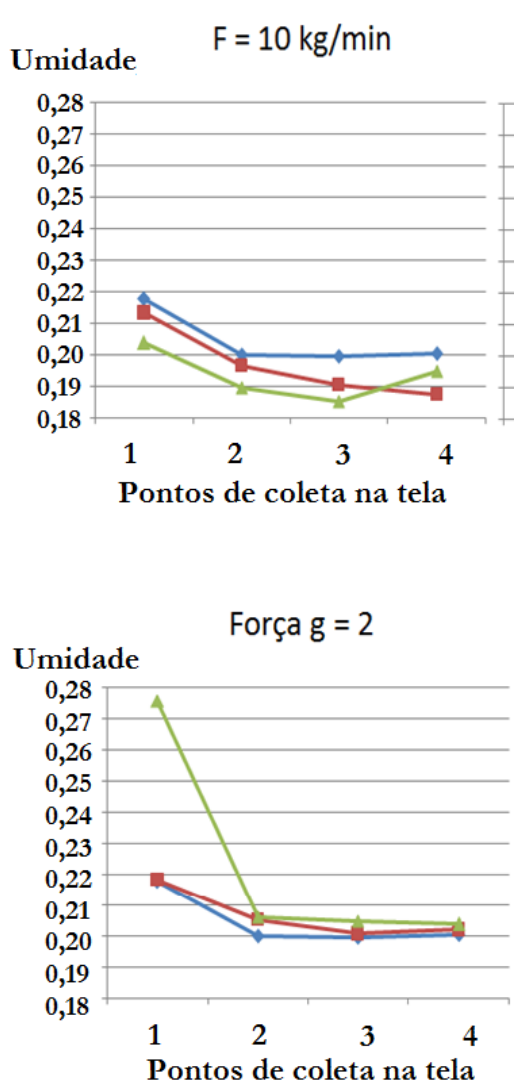

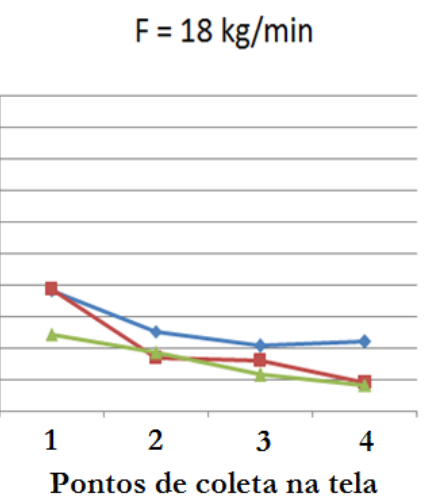

Pontos de coleta na tela
$\mathrm{F}=26 \mathrm{~kg} / \mathrm{min}$

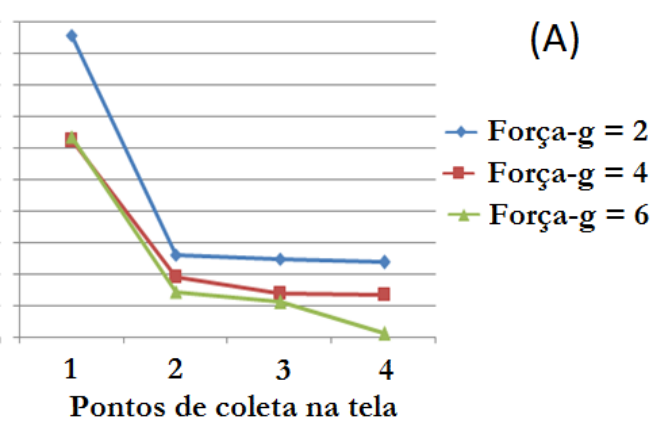

Força $g=6$

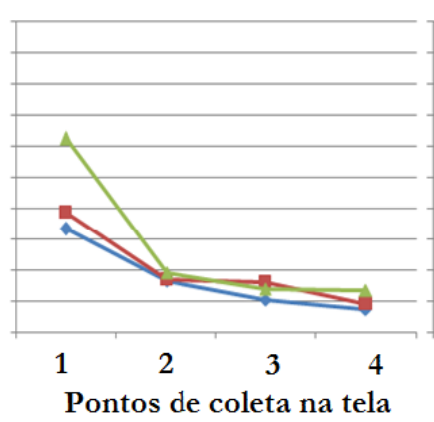

(B)

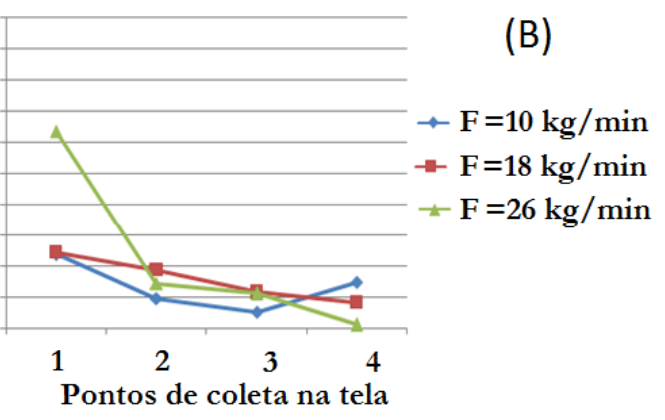

Os resultados apresentados nos gráficos são aqueles correspondentes às médias das triplicatas por ponto de coleta na tela de separação da peneira vibratória, para cada uma das condições operacionais testadas.

Com base na Figura 3 (A), pode-se perceber que o teor de umidade a partir do ponto de coleta número 2 varia menos de $1 \%$ quando se muda o valor da força-g, mantendo a vazão constante. Além disso, há um visível afastamento entre as curvas para os diferentes valores de força-g, com o teor de umidade decrescendo à medida que a força-g aumenta.

Já quando se varia a vazão, mantendo a força-g constante, como mostrado nos gráficos na figura 3(B), percebe-se que as curvas a partir do ponto 2 são mais próximas umas das outras, demonstrando que para os valores de vazão estudadas, não há influência significativa dos valores destas. Porém, pela disparidade apresentada pelos valores de umidade do material sólido retido sobre a tela de separação da peneira vibratória no ponto 1 , para as diferentes vazões testadas, fica claro que vazões maiores influenciam mais no avanço do fluído sobre a tela. 


\section{CONCLUSÃO}

Com base nos experimentos realizados foi possível verificar experimentalmente o comportamento do deságue da suspensão alimentada à tela de separação da peneira vibratória, sendo possível observar, através dos resultados, a influência da força- $g$ no processo de separação, sendo esta variável muito importante por estar diretamente ligada ao desgaste sofrido pela tela.

Além disso, foi possível verificar que a variável vazão possui menor influência sobre o processo para os valores estudados, demonstrando que a capacidade operacional da peneira é mais alta com as que se trabalhou.

\section{NOMENCLATURA}

$$
\begin{aligned}
& M_{S} \text {-Massa da amostra seca [-] } \\
& M_{H}-\text { Massa da amostra úmida [-] } \\
& \text { F - Vazão de alimentação }[\mathrm{kg} / \mathrm{min}] \\
& H \text { - Umidade residual do sólido retido [-] }
\end{aligned}
$$

\section{REFERÊNCIAS}

ASME - American Society of Mechanical Engineer, Drilling Fluid Processing Handbook.USA: Gulfprofessionalpublishing, Elsevier, 2005

GUERREIRO, F. S., BARBOSA, V. P., GEDRAITE, R., ATAÍDE, C. H. Estudo do efeito de variáveis operacionais sobre a eficiência de separação de um peneira vibratória em escala piloto.

GUERREIRO, F. S., BARBOSA, V. P., VARGAS, K. G., GEDRAITE, R., KUNIGK, L., ATAÍDE, C. H. Construção de bancada experimental para estudo do comportamento do teor de umidade residual presente no material retido utilizando peneira vibratória. Anais ENEMP 2015, 850 - 857, 2015.

MATTA, E. N. CIPELli, C. A. P., ASSiS, W. O., GOMES, M. M., BABRBOSA, V. P., ATAÍDE, C.H. Contribuição para o melhor aproveitamento de fluído de perfuração de poços de petróleo - Uma abordagem utilizando o processamento de imagem, Anais ENEMP 2015, 906 - 915, 2015.

LOBATO, F. S., OLIVEIRA-LOPES, L. C., GEDRAITE, R., NEIRO, S. M. S., MURATA, V. Identificação de modelos para unidades de recuperação do fluido de perfuração. IV Encontro Nacional de Hidráulica de Poços de Petróleo e Gás, Foz do Iguaçu - PR, 2011.

Raja, V., Chase, G. G., The University of Akron, Jones, B. N., Geehan, T., M-I SWACO Computaional Modeling and experiments on shale shaker performance. AADE American Association of Drillings Engineers, Conference USA, Houston, Texas, 2012 